\title{
DESIGN PAPER
}

\section{Development of a Smoke-Free Homes Intervention for Parents: An Intervention Mapping Approach}

\author{
Rachel O’Donnell*, Ruaraidh Dobson*, Marijn de Bruin ${ }^{\dagger}$, Stephen Turner ${ }^{\dagger}$, Lorna Booth \\ and Sean Semple*
}

Exposure to second-hand smoke (SHS) is associated with various ill-health outcomes for children and adults. Barriers to creating a smoke-free home (SFH) are well-documented. Feasible and effective interventions to create smoke-free homes for disadvantaged households are lacking. Interventions that include providing parents with objective information about the impact of smoking on air quality in their home may be particularly effective. This study describes the development of a novel, theory- and evidencebased smoke-free homes intervention using objectively-assessed air quality feedback. The intervention was developed using the six-step Intervention Mapping (IM) protocol. Findings from literature reviews, focus groups with parents, interviews with health/care professionals, and expert panel discussions shaped intervention content and materials. Findings highlighted the importance of parents receiving personalised information on second-hand smoke levels in their home. Professionals considered the use of non-judgemental language essential in developed materials. Previous literature highlighted the need to address home smoking behaviour at a household rather than individual level. The AFRESH intervention is modular and designed to be delivered face-to-face by healthcare professionals. It includes up to five meetings with parents, two sets of five days' air quality monitoring and personalised feedback, and the option to involve other household members in creating a smoke-free home using educational, motivational, and goal setting techniques. Further research is needed to evaluate the acceptability and effectiveness of the AFRESH intervention and which specific groups of parents this intervention will most likely benefit. IM was a useful framework for developing this complex intervention. This paper does not present evaluation findings.

Keywords: Intervention mapping; second-hand smoke; smoke-free home; air quality monitoring; children

\section{Introduction}

Exposure to second-hand smoke is associated with a widerange of preventable, adverse health outcomes in infants, children and adults. Inhaling second-hand smoke can lead to acute irritant and chronic inflammatory effects on the respiratory system, and is likely to be especially harmful during early life.

Fifteen percent of children living in the most deprived areas of Scotland are exposed to second-hand smoke in their homes, compared to close to zero percent of children living in the least deprived communities (Scottish Government 2016). Alongside this widening inequality in exposure, children in poorer communities in countries where smoke-free laws are partial or poorly enforced have seen almost no improvement in exposure levels. More than eighty-five percent of second-hand smoke is invisible (Gee et al. 2013), and recent work has shown that secondhand smoke remains in household air for up to five hours

\footnotetext{
* University of Stirling, GB

+ University of Aberdeen, GB

* Glasgow Caledonian University, GB

Corresponding author: Rachel O'Donnell (r.c.odonnell@stir.ac.uk)
}

after a cigarette is extinguished (Semple \& Latif 2014). Many smokers remain unaware of the impact of their smoking on air-quality in their home (Wilson et al. 2013a). Most smokers try to protect their children from secondhand smoke, often applying strategies that reduce rather than eliminate second-hand smoke risks completely, such as smoking at the kitchen window, or only smoking in the house when children are absent (Wilson et al. 2013a; Wilson et al. 2013b).

A recent systematic review and meta-analysis (Rosen et al. 2015) of interventions designed to reduce household second-hand smoke exposure identified seven interventions that had used objective measures of household air quality as an outcome measure. The meta-analysis demonstrated that these approaches improved air concentrations of fine particulate matter $\left(\mathrm{PM}_{2.5}\right)$ or nicotine within the home. However, all studies reported evidence of continued second-hand smoke exposure to some degree postintervention. More recently, a Cochrane review (Behbod et al. 2018) of interventions designed to reduce children's exposure to second-hand smoke in the home screened 78 relevant studies - only 24 of which reported a statistically significant intervention effect for reducing children's 
second-hand smoke exposure levels. Of these 24 studies, 13 used objective measures of children's second-hand smoke exposure, and the authors were unable to pinpoint what made these interventions effective. None of these studies used objective measures of household air quality $\left(\mathrm{PM}_{2.5}\right)$ as an outcome measure.

Several studies have explored the use of air quality feedback as a means of changing smoking behaviour in the home, and there is mixed evidence on the effectiveness of interventions using this approach in disadvantaged households. The REFRESH intervention showed considerable promise in a feasibility study (Wilson et al. 2013b) using face-to-face discussions between parents and health workers on why/how to make the home smoke-free. An air quality monitor was installed in each home, and parents received personalised air quality feedback to enhance their awareness of the impact of their smoking behaviour. Key barriers identified were instrumentation cost and the labour-intensive method of intervention delivery, which involved researchers conducting home visits to install and retrieve air quality monitoring devices. The intervention had developed organically based on experience developed over the years, and did not make full use of existing theories and evidence on behaviour change.

Based on REFRESH, a recent randomised controlled trial (Semple et al. 2018) examined whether delivery of personalised air quality feedback plus standard advice on the health effects of second-hand smoke was more effective than standard advice alone in helping disadvantaged mothers protect their children from second-hand smoke. The intervention was embedded within the National Health Service (NHS) Lanarkshire First Steps (FS) early intervention programme, overcoming the labour-intensive delivery methods used in REFRESH. Neither standard advice nor standard advice plus air quality feedback were effective in reducing $\mathrm{PM}_{2.5}$ concentrations. This may reflect the intervention targeting young mothers, despite the fact that in many households, other adults (partners, parents and visitors) also smoked in the home. The authors conclude that future work should consider ways to engage with all adults in the home to achieve sustained household behaviour change in relation to smoking. Another recent randomised controlled trial (Ratschen et al. 2018) tested a complex intervention based on other feasibility work (Marsh et al. 2016), providing families with personalised feedback on home air quality, behavioural support and nicotine replacement therapy for temporary abstinence. This approach was effective in significantly reducing children's exposure to second-hand smoke in the home, and most participants ranked the personalised air quality feedback as the single most important intervention component.

Interventions using personalised air quality feedback to reduce children's exposure to second-hand smoke have found mixed evidence of effectiveness. Recent work has highlighted the complex interplay that exists between barriers, motivators and enablers to creating a smokefree home in many households, which can make this a difficult achievement (Rowa-Dewar, Lumsdaine \& Amos 2015; Passey et al. 2016). However, developing effective interventions that enable parents to create a smoke-free home is one of the key ways that children's exposure to second-hand smoke can be reduced globally. A recent call (Conner \& Norman 2017) has been made for a greater focus on developing and testing theory-based, rather than "theory inspired" (Michie \& Abraham 2004) interventions to advance research on effective health behaviour change. Smoke-free home interventions have yet to make optimal use of existing behaviour change theories. Our study aimed to develop a theory-based intervention programme to reduce second-hand smoke levels in the home (AFRESH), utilising personalised air quality feedback. To address an identified gap in previous research in this area, the intervention was developed for health/care professionals (e.g. family nurses, early years' workers) to use with parents who wish to move towards having a smoke-free home, and other household members who smoke in the home.

\section{Intervention Mapping}

Intervention Mapping (IM) is a widely-used framework for developing (complex) behaviour change interventions based on theory, empirical evidence, and input from key stakeholders (Bartholomew et al. 2016). This framework was chosen to develop AFRESH as it details the methods that are suitable for changing important behavioural determinants such as knowledge, attitude and selfefficacy, and how these methods should be applied for optimal effectiveness. IM ensures all components in the programme development process are transparent, linked, and supported by a clear rationale for each choice based on theory, evidence, and/or expert opinion. For the replicability and future synthesis of interventions, it is important that detailed descriptions of the interventions and the process of their development are published (Bartholomew et al. 2016; Schaalma \& Kok 2009). IM comprises of six steps, each with several specific tasks (see Figure 1). This manuscript reports on the development of AFRESH using Steps 1 to 4 . Steps 5 and 6 focus on implementation and evaluation plans. The results of piloting AFRESH are reported elsewhere (Dobson et al. 2017).

\section{Methods and Results \\ Step 1: Needs Assessment}

Method

A planning group was established with academics and researchers involved in previous second-hand smokerelated research, NHS Board representatives, and relevant non-profit organisations. A member of our research team spoke informally with each group member about their prior experiences of delivering air quality interventions. These discussions informed the development of topic guides and interview schedules used in Stage 4 (see Supplementary file 1 - Interview schedule for use with health and care professionals, and Supplementary file 2 - Parent focus group topic guide).

We also conducted 1) a rapid review of the literature on behavioural interventions to reduce indoor smoking by parents; 2) a rapid review of interventions that use feedback of objectively assessed data to elicit health behaviour change; and 3) a secondary analysis of previous qualitative 


\begin{tabular}{|c|c|c|c|}
\hline \multirow[t]{3}{*}{$\begin{array}{l}\text { Step 1: Needs } \\
\text { assessment }\end{array}$} & \multirow{3}{*}{$\begin{array}{l}\text { 1. Establish planning group } \\
\text { and assess capacity } \\
\text { 2. Conduct needs } \\
\text { assessment } \\
\text { 3. Establish programme } \\
\text { outcomes }\end{array}$} & \multicolumn{2}{|c|}{$\begin{array}{l}\text { 1. Planning group comprising academics, researchers, NHS } \\
\text { Health Board representatives, and third sector organisations } \\
\text { established. Capacity assessed via discussions with group. }\end{array}$} \\
\hline & & \multicolumn{2}{|c|}{$\begin{array}{l}\text { 2. Rapid reviews of (1) behavioural interventions to reduce } \\
\text { indoor smoking by parents and (2) interventions using feedback } \\
\text { of objectively assessed data to elicit health behaviour change } \\
\text { Secondary analysis of qualitative research on SHS in the home. } \\
\text { Created a logic model of the problem }\end{array}$} \\
\hline & & \multicolumn{2}{|c|}{$\begin{array}{l}\text { 3. Overall programme aim defined as parents making the home } \\
\text { entirely smoke-free. }\end{array}$} \\
\hline \multirow[t]{4}{*}{ Step 2: Matrices } & \multirow{4}{*}{$\begin{array}{l}\text { 1. State expected changes } \\
\text { in behaviour and } \\
\text { environment } \\
\text { 2. Specify performance } \\
\text { objectives } \\
\text { 3. Specify determinants of } \\
\text { the target behaviour of the } \\
\text { at risk group } \\
\text { 4. Create matrices of } \\
\text { change objectives }\end{array}$} & \multicolumn{2}{|c|}{$\begin{array}{l}\text { 1. Created a logic model of change } \\
\text { Two specific outcomes developed using SMART outcomes. }\end{array}$} \\
\hline & & \multicolumn{2}{|c|}{$\begin{array}{l}\text { 2. Eight performance objectives specified for parents as the } \\
\text { active participants in the intervention }(\mathrm{N}=4) \text { and for parents as } \\
\text { the persons who will extend intervention delivery to other } \\
\text { household members ( } N=4) \text {. }\end{array}$} \\
\hline & & \multicolumn{2}{|c|}{$\begin{array}{l}\text { 3. Six determinants specified for parents as the participants in } \\
\text { the intervention; three specified for parents as those extending } \\
\text { the intervention delivery to other household members. }\end{array}$} \\
\hline & & \multicolumn{2}{|c|}{$\begin{array}{l}\text { 4. Eight performance objectives were mapped to the nine } \\
\text { determinants to create matrices of change objectives. }\end{array}$} \\
\hline \multirow{3}{*}{$\begin{array}{l}\text { Step 3: Theory- } \\
\text { based methods } \\
\text { and practical } \\
\text { strategies }\end{array}$} & \multirow{3}{*}{$\begin{array}{l}\text { 1. Review programme } \\
\text { ideas with planning group } \\
\text { 2. Identify theoretical } \\
\text { models } \\
\text { 3. Choose programme } \\
\text { methods } \\
\text { 4. Select/design strategies } \\
\text { 5.Ensure that strategies } \\
\text { match change objectives }\end{array}$} & \multicolumn{2}{|c|}{$\begin{array}{l}\text { 1. Planning group reviewed potential behaviour change } \\
\text { techniques and practical methods. }\end{array}$} \\
\hline & & \multicolumn{2}{|c|}{$\begin{array}{l}\text { 2. Each determinant mapped to the relevant domain within the } \\
\text { taxonomy for intervention development. Four relevant } \\
\text { theoretical models identified. }\end{array}$} \\
\hline & & \multicolumn{2}{|c|}{$\begin{array}{l}\text { 3. Five behaviour change techniques were selected from the } \\
\text { taxonomy for their potential application in changing our } \\
\text { identified determinants and associated change objectives. }\end{array}$} \\
\hline $\begin{array}{l}\text { Step 4: } \\
\text { Programme }\end{array}$ & $\begin{array}{l}\text { 1. Consult with intended } \\
\text { participants/implementers } \\
\text { 2. Create programme } \\
\text { scope, sequence, materials. } \\
\text { 3. Develop/design } \\
\text { documents and protocols } \\
\text { 4. Review available } \\
\text { materials } \\
\text { 5. Develop materials } \\
\text { 6. Pretest materials with } \\
\text { target groups and oversee } \\
\text { materials production }\end{array}$ & \multicolumn{2}{|c|}{$\begin{array}{l}\text { 1. Seven interviews with professionals who had previous } \\
\text { experience in using air quality monitors to support parents } \\
\text { make their homes smoke-free. Three focus groups with parents } \\
\text { ( } \mathrm{n}=15 \text { ) from disadvantaged areas to identify preferences for } \\
\text { visual feedback from the air quality monitors. } \\
\text { 2. Air quality feedback package and visualisations developed on } \\
\text { basis of interviews/focus groups. Software developed to enable } \\
\text { download/interpretation of air quality data with parents. } \\
\text { 3-6. Programme content developed - } 6 \text { modules designed to be } \\
\text { delivered using face to face discussion techniques, alongside } \\
\text { baseline and follow up measures of household SHS levels. } \\
\text { Programme manual produced (see Supplementary file } 7 \text { ) } \\
\text { providing practical information on how to work with parents } \\
\text { through the programme, and use the intervention materials. }\end{array}$} \\
\hline $\begin{array}{l}\text { Step 5: Plan } \\
\text { adoption and } \\
\text { implementation }\end{array}$ & \multicolumn{2}{|c|}{$\begin{array}{l}\text { 1. Identify adopters and users. } 2 \text {. Specify adoption, implementation \& } \\
\text { sustainability performance objectives. } 3 \text {. Specify determinants and create } \\
\text { matrix. } 4 \text {. Select methods and strategies. } 5 \text {. Design interventions to affect } \\
\text { programme use. }\end{array}$} & $\begin{array}{l}\text { The methods } \\
\text { and results } \\
\text { associated with } \\
\text { Steps } 5 \text { and } 6\end{array}$ \\
\hline $\begin{array}{l}\text { Step 6: } \\
\text { Evaluation plan }\end{array}$ & \multicolumn{2}{|c|}{$\begin{array}{l}\text { 1. Describe the programme. 2. Describe programme outcomes and effect } \\
\text { questions. 3. Write questions based on matrix. } 4 \text {. Write process questions. } \\
5 \text {. Develop indicators and measures. } 6 \text {. Specify evaluation measures. }\end{array}$} & $\begin{array}{l}\text { are reported } \\
\text { elsewhere. }\end{array}$ \\
\hline
\end{tabular}

Figure 1: Intervention mapping steps and tasks.

research regarding reasons for reducing second-hand smoke in the home. These sources of information were utilised not only in the needs assessment, but also in later steps in the intervention development process.

During Step 1, the following literature reviews were developed:

- AFRESH review of behavioural interventions to reduce indoor smoking by parents (2016) (see Supplementary file 3)

- AFRESH review of successful interventions that have used objectively assessed feedback to motivate health behaviour change (2016) (see Supplementary file 4)

- AFRESH secondary analysis of qualitative data: second-hand smoke exposure in the home (2016) (see Supplementary file 5)

- Details of the literature search strategies are provided in Supplementary file 6.

Results

Literature reviews: reasons for smoking indoors

Smoking restrictions in the home are shaped by a range of sociocultural influences and other factors that create enablers, and barriers for future public health initiatives.
The reviews identified that people do not automatically make the connection between the (extent of) risks of second-hand smoke and their smoking behaviour in the home (Rowa-Dewar, Lumsdaine \& Amos 2015). However, most parents state that they are aware that children are more vulnerable, and that they want to protect their children's health (Wilson 2013a). Living circumstances seem to have a major impact on the reduction of second-hand smoke in the home; for example, living in a block of flats and being unable to leave the children alone to go outside to smoke. Qualitative review findings also suggested that parent/carers' level of knowledge, awareness and risk perception are themes that should be considered when developing future second-hand smoke reduction intervention studies, which should also encourage positive social norms (good parenting), tackle negative social norms and address negative feelings of stigmatisation (Passey et al. 2016; Phillips et al. 2007; Rowa-Dewar, Lumsdaine \& Amos 2015; Wilson et al. 2013a). The key factors identified as reasons for smoking indoors during the Step 1 needs assessment work are displayed in a logic model of the problem (see Figure 2).

Given that the World Health Organisation recognises there is no safe level of exposure to second-hand smoke in the home (WHO Framework Convention Alliance for 


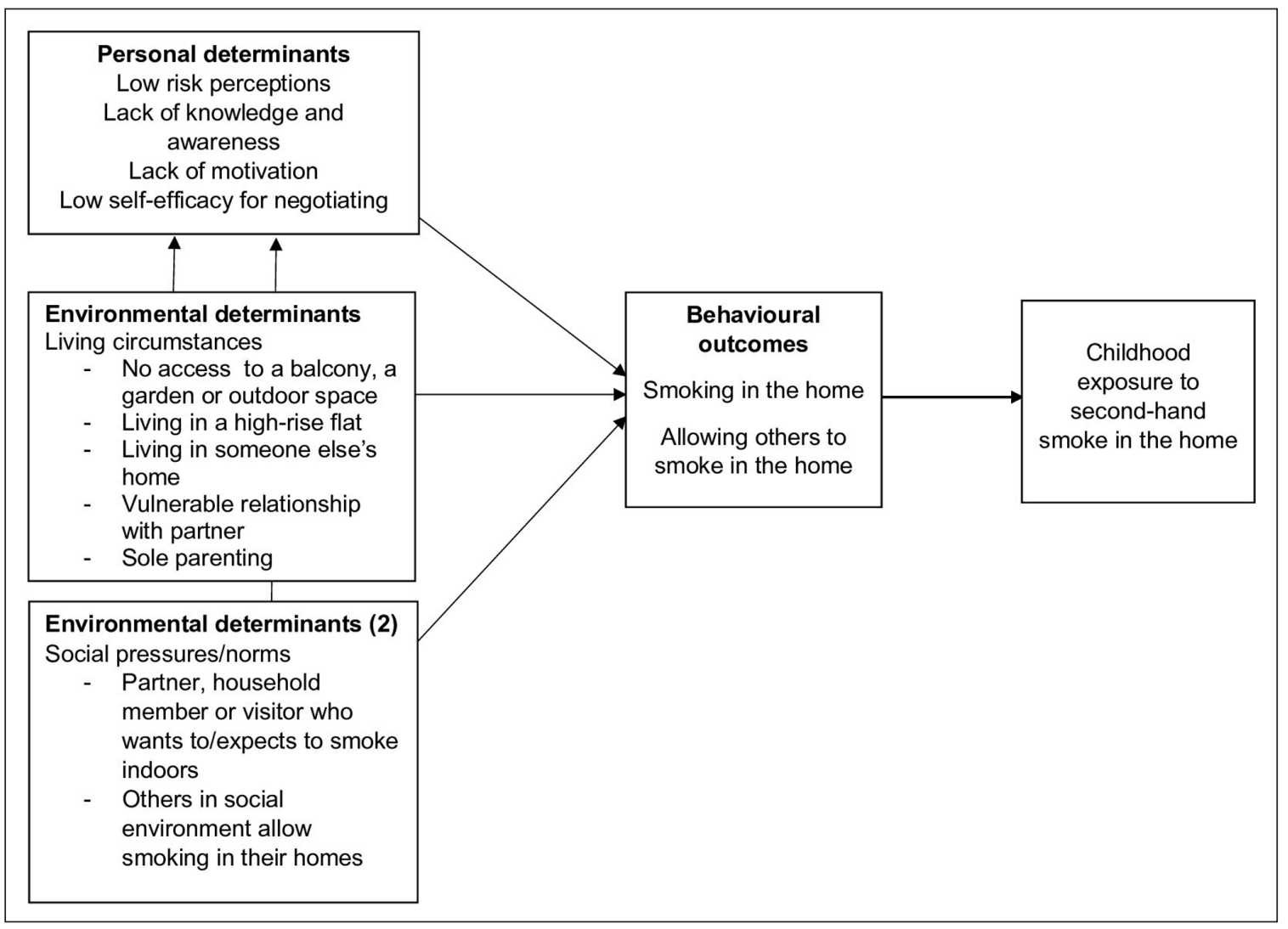

Figure 2: Logic model of the problem.

Tobacco Control, 2005), the research team agreed that the overall programme aim is to have parents make the home entirely smoke-free. Our previous work has identified that health/care professionals are the desired delivery personnel for this type intervention. This was also the finding of our review of second-hand smoke interventions, which highlighted that successful feedback interventions involved face-to-face communications with health/care professionals (Bovet et al. 2002; De Blok et al. 2006). Incorporating objectively assessed data and motivational interviewing (MI) appear to be the most popular adopted intervention methods and the most effective for secondhand smoke reduction with parents and caregivers of young children (Baheiraei et al. 2011; Emmons et al. 2001; Harutyunyan et al. 2013; Wilson et al. 2013b).

\section{IM Step 2: Creating matrices of change Method}

The tasks in step 2 (see Figure 1) were completed through discussion, consulting the literature and behaviour change theory. Two specific outcomes for the behaviour of the target group were developed using SMART (specific, measurable, achievable, realistic and timely) outcomes. Outcome 1 was developed using published literature on the outcomes of smoke-free homes interventions as a guide, and specifies that within three months of intervention initiation, $40 \%$ of participating parents no longer smoke indoors. Previous studies have suggested that the smoking behaviours of other household members should not be overlooked in any second-hand smoking intervention, as a 'household approach' to creating smoke-free homes may be more effective than an individualised approach in households where more than one adult smokes (Brown et al. 2015; Semple et al. 2018). On this basis and given the lack of published smoke-free homes research that includes partners/other household members as active participants, 'participating parents' (Outcome 1) also includes partners and other adult household members who smoke. Outcome 2 was developed through research team discussions, and states that within three months of intervention initiation, parents/carers engaged in the intervention will have engaged with as many partners/other household members who smoke as possible, to convince them to no longer smoke indoors. A logic model of change was created to summarise the desired outcomes of the intervention (see Figure 3).

Our review findings demonstrated that central to our behaviour change intervention is parents' intrinsic motivation to protect their children and be considered by others as a good parent (Wilson et al. 2013a; Wilson et al. 2013b) and the importance of behavioural feedback and self-monitoring in self-regulating behaviour (de Bruin et al. 2012), provided here through the air quality monitor. Self-determination Theory (SDT) (Deci \& Ryan 1985) and Control Theory (Carver \& Scheier 1982; Carver \& Scheier, 1998) were therefore selected as the key theories to guide the development of our intervention. The outputs of Step 2 were placed in matrices of change objectives, which detail exactly what changes need to be accomplished to achieve the overall desired outcome of the intervention - the creation of smoke-free homes, and the SMART outcomes outlined above. 


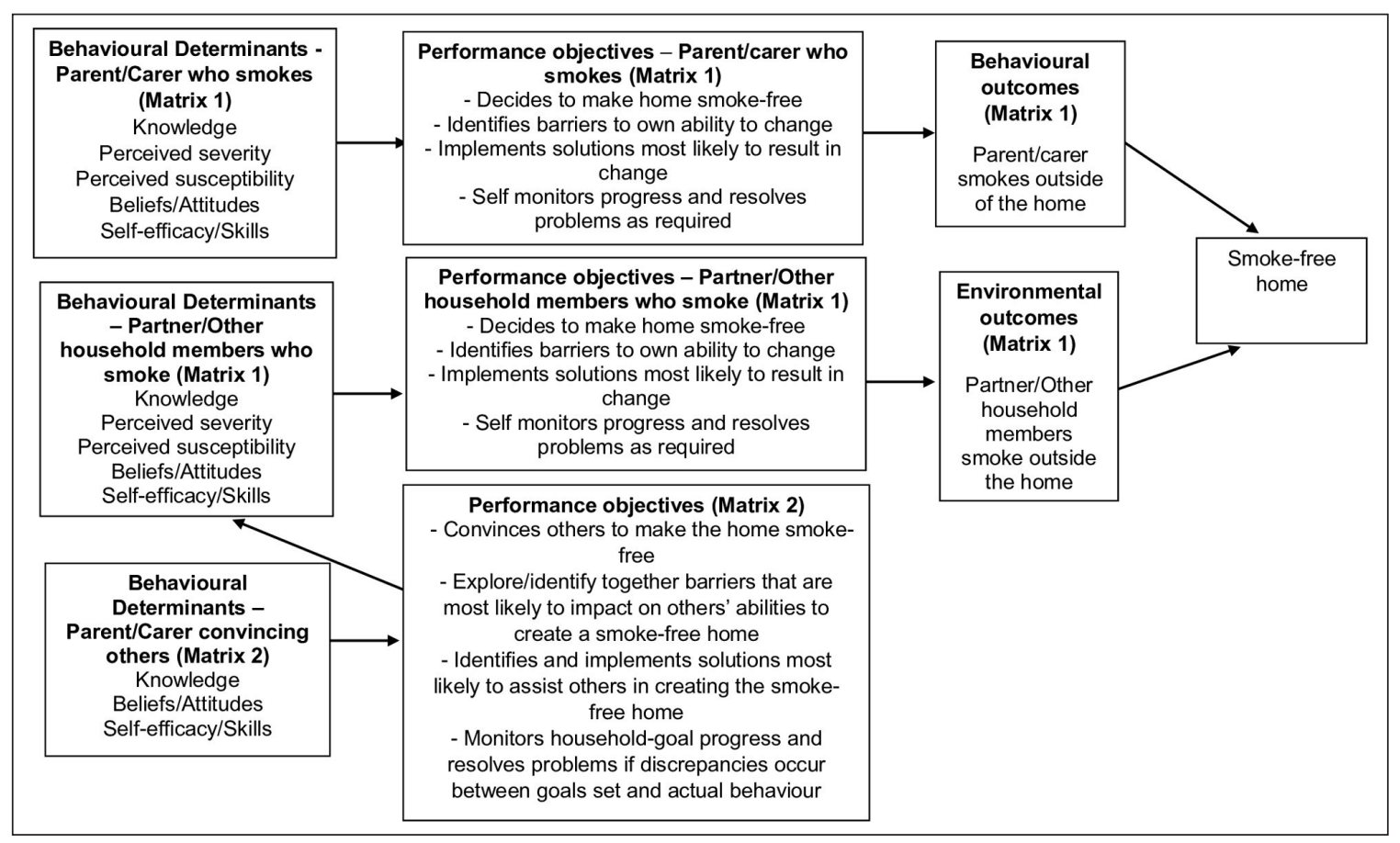

Figure 3: Logic model of change.

Results

Two matrices are provided in Tables $\mathbf{1}$ and 2 . The first applies to parents (mothers, fathers or step-parents) who are the participants in the intervention, and the partners/other household members who they persuade to create a smoke-free home. The second matrix outlines the steps required for parents to effectively extend intervention delivery to other household members who smoke. Although Matrix 2 could also be considered as part of intervention implementation (Step 5), it directly addresses issues identified in the needs assessment and is therefore included here. Performance objectives, which are sub-behaviours or actions that should result in the final health behaviour of making the home smoke free are given in column 1 of Tables $\mathbf{1}$ and 2 . In the top column, the most important and changeable determinants of behaviour change are given. Wherever the behavioural determinants were judged to be relevant for that particular behaviour, a change objective was formulated.

Each of the performance objectives, determinants and change objectives were derived from existing literature, our review work, interviews, and expert input, in combination with SDT and Control Theory as our main theories. For example, the performance objective 'Decide to make home smoke-free' (see Table 1) reflects the setting of a goal following a motivational process (Carver \& Scheier 1982; Carver \& Scheier, 1988). For this performance objective, the determinants knowledge, risk perception (susceptibility and severity), beliefs/attitudes and selfefficacy/skills were identified to be important, based on previous literature (Passey et al. 2016; Phillips et al. 2007; Rowa-Dewar, Lumsdaine \& Amos 2015; Wilson et al. 2013a). Associated change objectives formulated through team discussion were 'Explain the health risks associated with childhood second-hand smoke exposure in the home', 'Explain that there is no safe level of exposure to second-hand smoke' and 'Recall the strategies that are ineffective in removing risk completely'. The performance objective 'Self-monitor goal progress and respond by resolving problems if discrepancies occur between the goals set and actual behaviour' (see Table 1) was also derived from control theory, i.e. that people have a goal in mind and try to move towards it, are more successful in achieving their goals if they monitor their progress towards this goal, and take steps to reduce the discrepancy between their goal and actual behaviour as required (Carver \& Scheier 1982; Carver \& Scheier 1998).

SDT is particularly focused on the ways in which an individual acquires the motivation for initiating behaviour change, and maintaining new behaviours over time. The theory argues that developing a sense of autonomy, competence and relatedness are critical to the process of 'internalisation' - the process by which behaviours become more autonomously regulated, or valued, over time. According to SDT, the least internalised form of regulation is 'external', and reflects engaging in behaviours to gain some reward or recognition (for example, an individual creating a smoke-free home in order to receive a financial incentive, or because a health care practitioner pressures them to do so). In such instances, long-term health behaviour change is unlikely (Ng et al. 2012). The most internalised form of regulation is 'integrated', and reflects engaging in behaviours because they are consistent with an individual's own goals and values (for example, creating a smoke-free home because an individual values the health of their children, and because this behaviour is consistent with other goals in their life such as reducing cigarette consumption) (Patrick \& Williams 2012). Engaging in health behaviours for more autonomous reasons is likely to result in better behavioural adoption and 


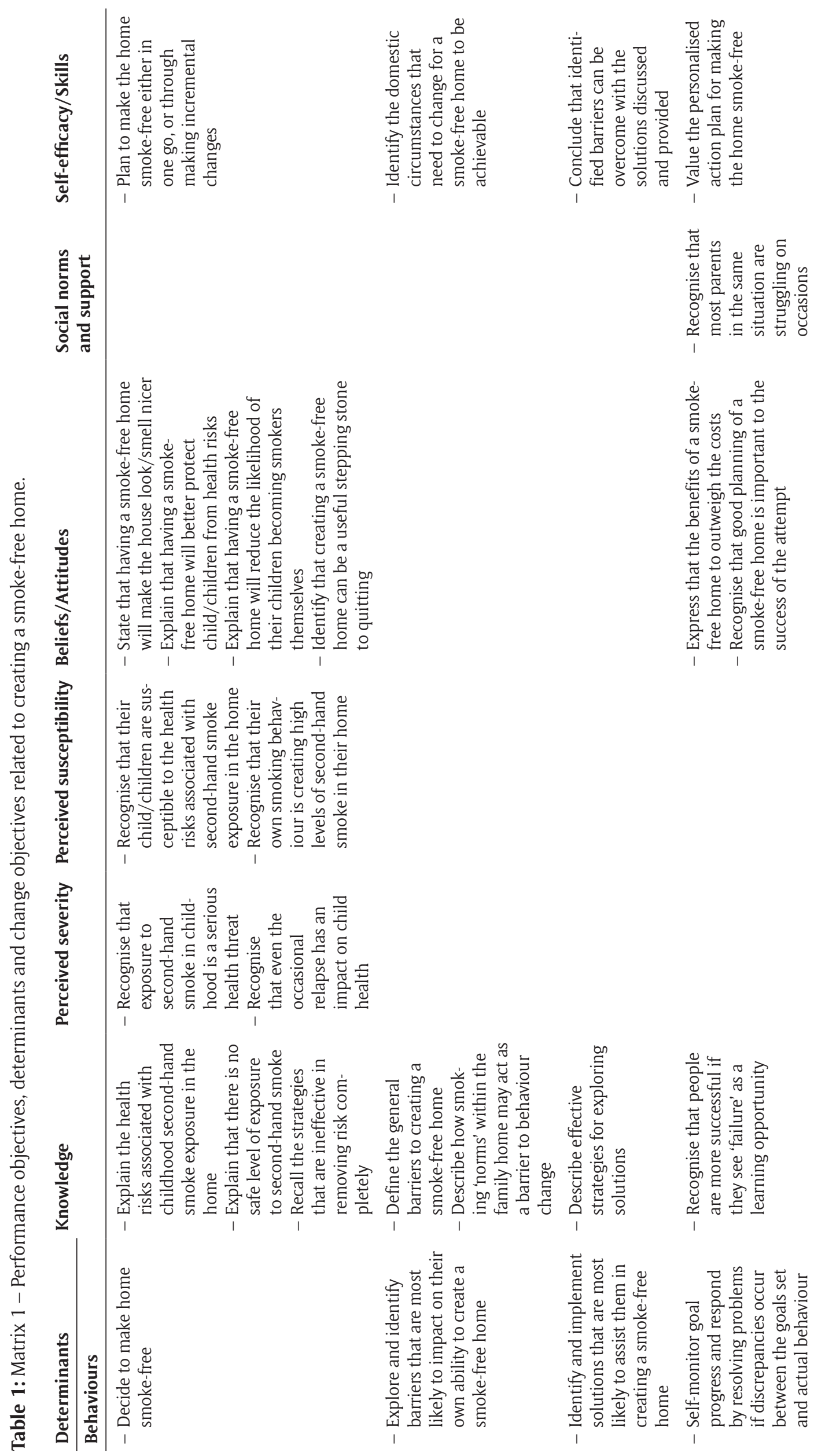




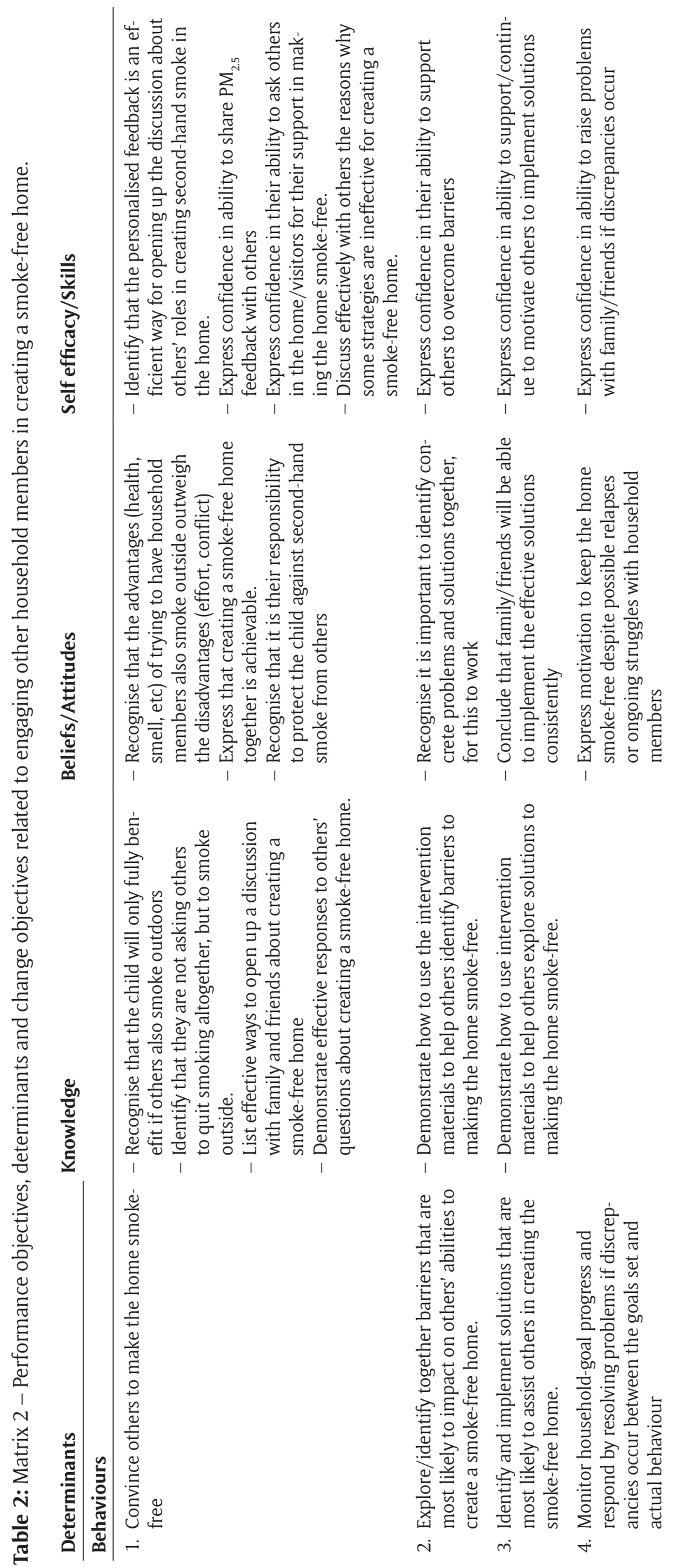


maintenance (Deci \& Ryan 2008). Previous research has also suggested that combining MI approaches with the theoretical approach of SDT may elicit greater behaviour change (i.e. Deci \& Ryan 2012; Patrick \& Williams 2012). MI can be used to put the theoretical foundation of SDT - attainment of competence, autonomy and relatedness into practice (Vansteenkiste et al. 2012).

We used the principles of SDT to seek to strengthen parents/carers' personal motivation for and commitment to creating a smoke-free home by eliciting and exploring individual reasons for change. The rationale is thus that if the intervention is successful in increasing autonomous behaviours (the extent to which behaviours originate from the self), parents/carers will be more likely to decide to create and maintain their smoke-free home. On this basis, SDT was used to develop the performance objectives 'Explore and identify barriers that are most likely to impact on their own ability to create a smoke-free home' and 'Identify and implement solutions that are most likely to assist them in creating a smoke-free home', which support autonomy through eliciting and acknowledging individuals' perspectives regarding their own barriers and solutions, whilst minimising control and avoiding judgement (Patrick \& Williams 2012). Other components of the intervention fit well with SDT, for example the change objectives 'Recognise that people are more successful if they see 'failure' as a learning opportunity' and 'Recognise that most parents in the same situation are struggling on occasions' (associated with the 'Self-monitor goal progress...' performance objective), as they provide support for competence (reframing past failures as short successes and being positive that individuals can succeed) and relatedness (providing unconditional positive regard, particularly in the face of failure to achieve desired goals) (Patrick \& Williams 2012).

\section{IM Step 3: Theoretical methods and practical strategies Method}

The tasks in Step 3 (see Figure 1) were completed using Bartholomew et al.'s (1998) taxonomy for intervention development, published by Kok et al. (2016) and extracted from Bartholomew et al.'s (2011) Intervention Mapping protocol. This taxonomy details the methods that are suitable for changing important behavioural determinants (such as knowledge, attitude, or self-efficacy), and how these methods should be applied for optimal effectiveness. Given our focus on translating intentions into behaviour, we identified behaviour change methods from the trans-theoretical model, goal setting theory, and theories of self-regulation to underpin the intervention, in conjunction with theories of information processing. Our main behaviour change intervention methods were discussion, elaboration, individualisation, goal setting and planning coping responses. These decisions were supported by our literature review work. For example, planning coping responses is listed in the taxonomy as a suitable method to change self-efficacy and overcome barriers. This requires prompting participants to list potential barriers and ways to overcome these. It also involves identification of high-risk situations and practice of cop- ing responses. The use of this method is also supported by research by Passey et al. (2016), who recommend that professionals should be trained to develop skills in advising on smoke-free home-related practical strategies, for example, how to overcome weather-related barriers, to support households in creating a smoke-free home. The methods selected also linked back to Control Theory. For example, to change social norms and support, individuals are encouraged to develop effective solutions for dealing with social pressure that may hinder change, and to increase self-efficacy/skills, individuals are prompted to list potential barriers and overcome them. The discussion and elaboration methods used to increase knowledge and change beliefs/attitudes drew on MI techniques and SDT, designed to strengthen personal motivation for and commitment to creating a smoke-free home by exploring the parent/carer's own reasons for change with a compassionate approach.

\section{Results}

Table 3 shows examples of our determinants, theoretical methods, and their parameters for use and practical applications. Each behaviour change method was considered for its potential application in changing our identified determinants and the change objectives associated with them. These matrices also enabled us to consider what an intervention might look like if we incorporated each specific behaviour change method. A full list of the behaviour change methods selected for each determinant and associated change objectives is presented in Table 4.

For example (see Table 3), for the determinant 'Knowledge' and the change objective 'Explain the health risks associated with childhood second-hand smoke exposure in the home', we selected the 'Discussion' method, which encourages consideration of a topic in an open, informal debate. Its parameters involve listening to the learner to ensure that the correct schemas are activated. Practical application of this method in our intervention therefore involved an informal discussion of the health risks, barriers and solutions for creating a smoke-free home.

\section{IM Step 4: Programme development}

\section{Method}

The tasks in Step 4 were completed benefiting from previously developed materials in REFRESH (Wilson et al. 2013b) and the intervention literature review. To assist in developing intervention materials, including the specifics of the personalised air quality feedback, seven semistructured interviews were conducted with health and care professionals who had previous experience in using air quality monitors to support parents making their homes smoke-free. The purpose of the interviews was to elicit their views on the practicalities, challenges and benefits using air quality monitors with parents; the best ways in which to deliver smoke-free homes interventions, the impacts of current visual feedback tools and whether they could be improved, and preferred delivery mode for future smoke-free homes interventions. Detailed notes were taken during each interview by the interviewer. 


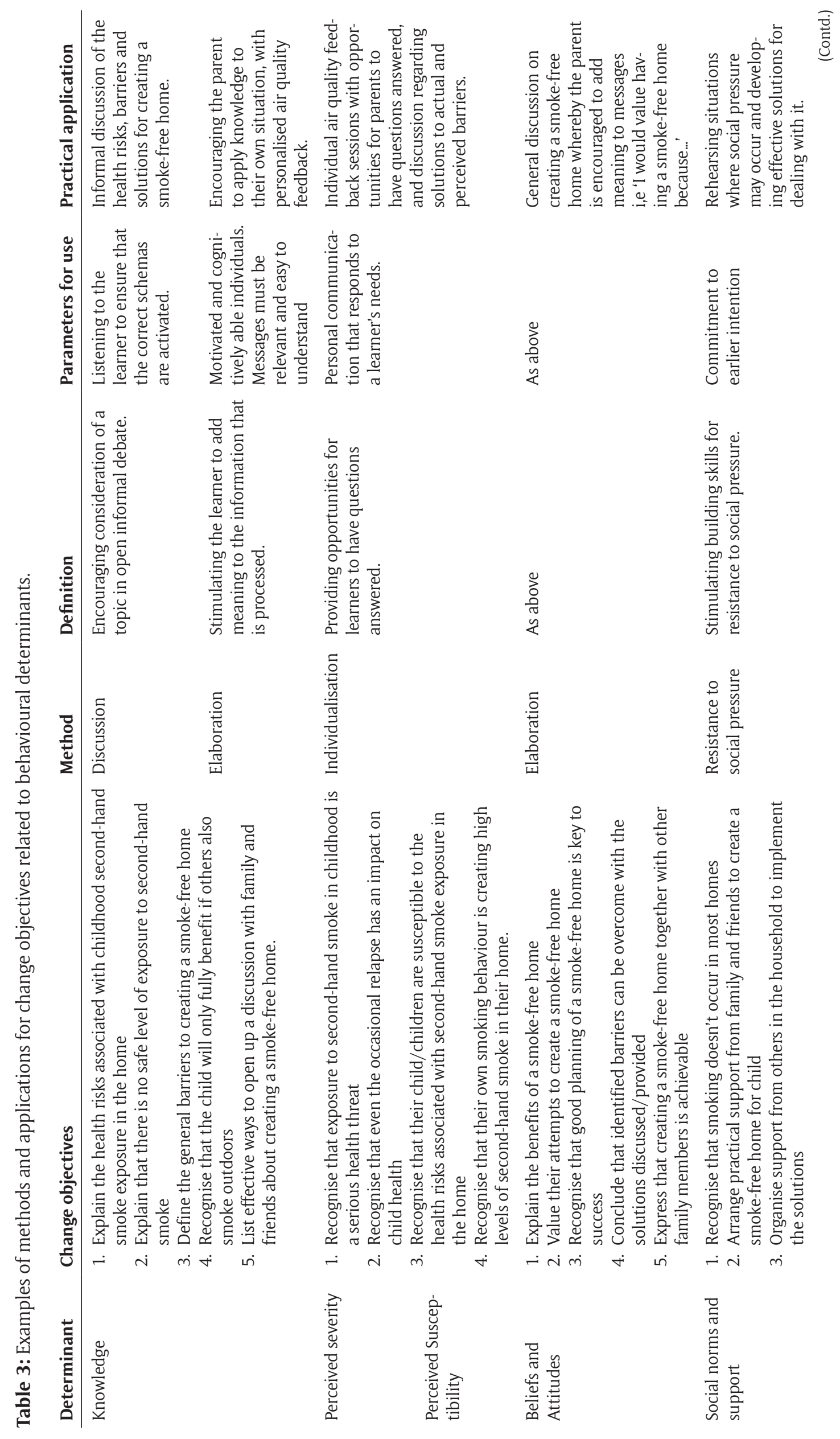



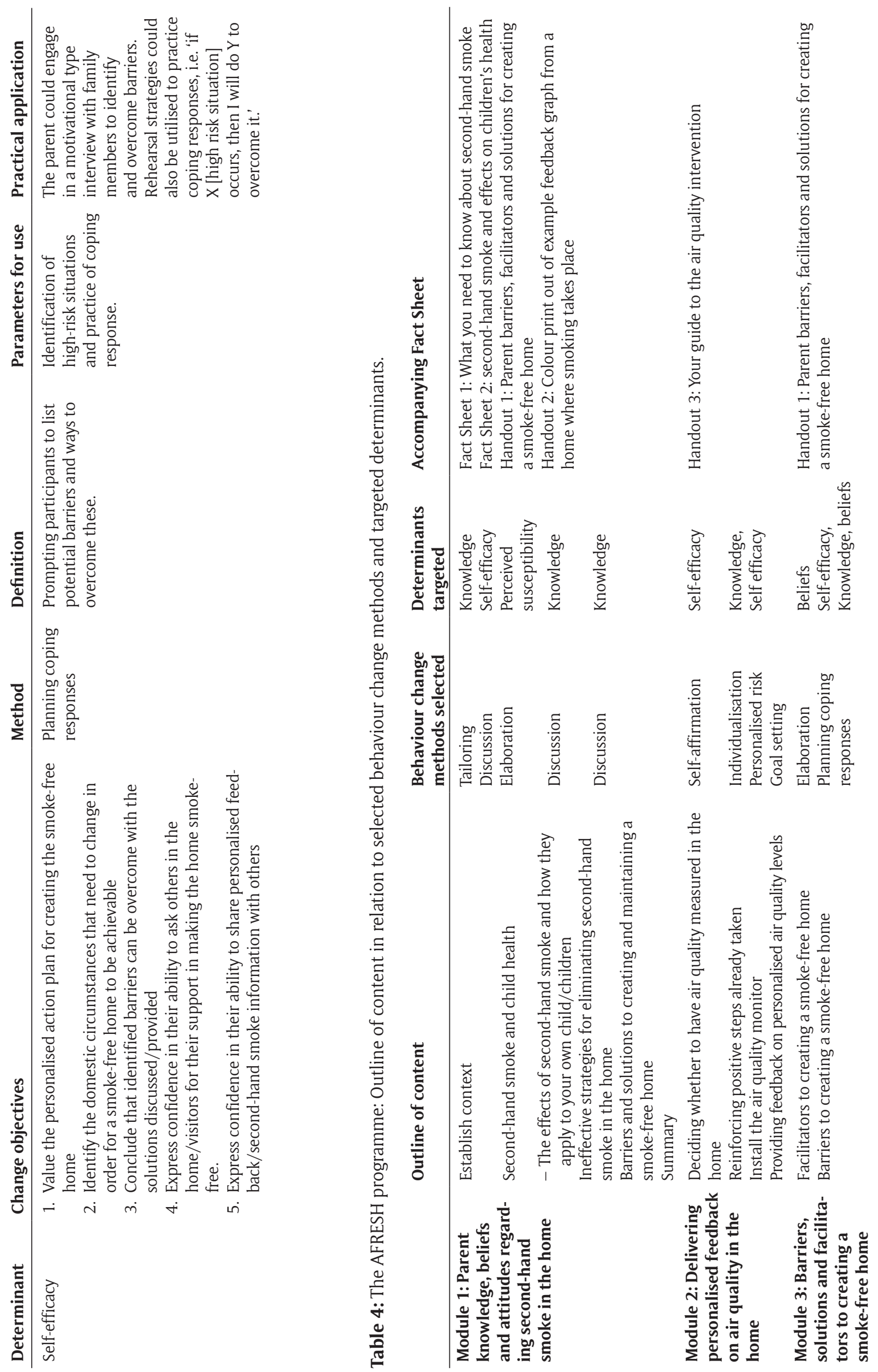


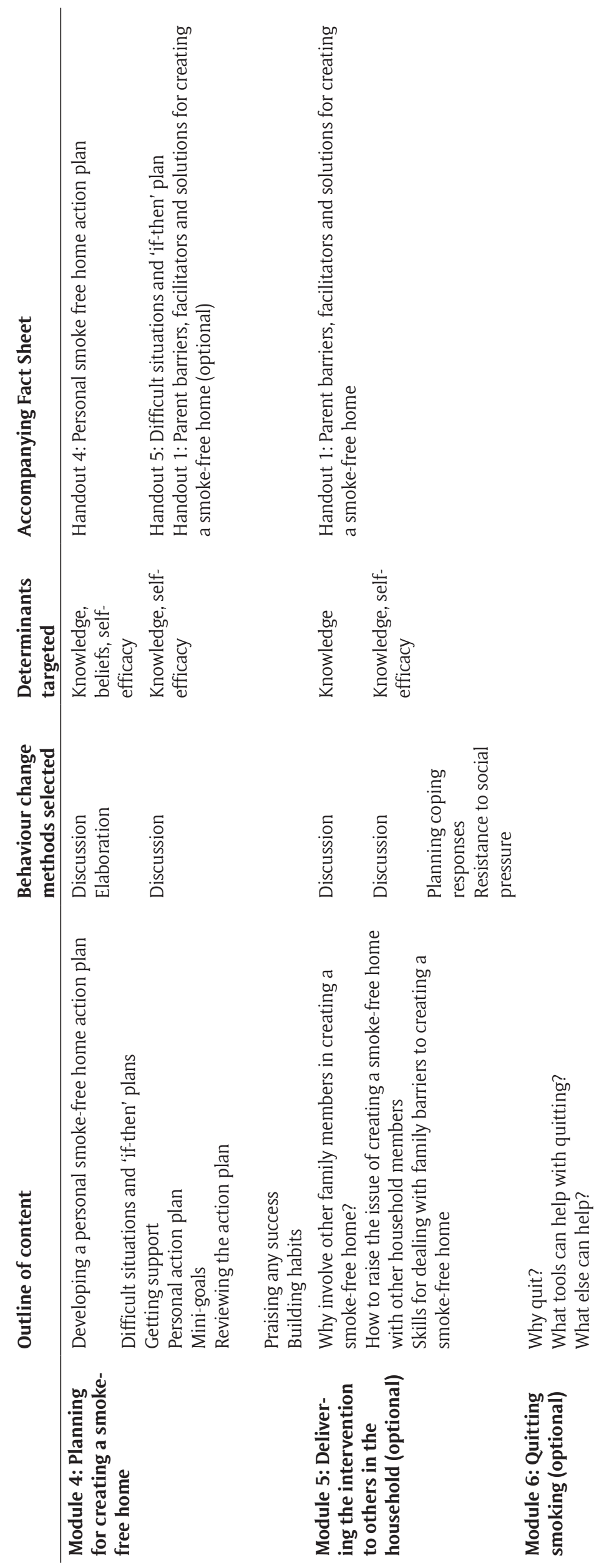


These notes were then written up and key themes were identified and agreed across interviews by two members of the team.

Three focus groups were conducted with parents $(n=15)$ from disadvantaged urban areas, between March-April 2016, to identify preferences for visual feedback from the air quality monitors. Parents were recruited via gatekeepers from two community groups that work with families in disadvantaged areas to promote positive health and wellbeing. Gatekeepers identified potential participants, distributed invitation letters and information sheets to them and liaised with the researcher to set up suitable focus group times and dates. All focus groups took place within the community centres during usual group meeting times. Written consent was obtained from each participant before the start of each focus group. All parents who took part either smoked, or lived with someone who smoked, and had one or more children under the age of five.

We did not aim to recruit a representative population sample for this phase of the study. Instead, we recruited participants from groups that had no prior experience of having their air quality measured. Some had established smoking restrictions in their own homes, but others had experienced barriers in doing so, relating to sole-parenting, lack of outdoor home space, or lack of motivation. The focus groups included a brief introduction to air quality monitoring as a means of reducing second-hand smoke exposure in the home. Parents were asked for their views on current air quality feedback packages used with a view to improving the current feedback package outlined in
Figures 4-6. The discussion elicited parents' views on ease of understanding the graphs, their views on presenting personalised air quality feedback as a motivational tool for health behaviour change, and their preferences for receiving personalised feedback across a 24 hour period, a one week period, or both. The focus group discussions were digitally audio-recorded and transcribed. Two members of the research team identified key themes independently, which were then discussed with agreement reached on findings and their implications for programme development. Ethical approval was obtained from the University of Aberdeen College Ethics Review Board.

Results

i. Format of delivery

Professionals agreed that providing parents with personalised air quality feedback is credible, and that providing 'proof' of indoor second-hand smoke levels has the potential to change smoking behaviour and reduce second-hand smoke levels in the home. This finding was supported by our rapid review of successful interventions using objectively assessed feedback to motivate health behaviour change, which found that presenting personalised feedback to individuals may increase motivation to change their health behaviour by removing the perception of the alternative health risks as hypothetical (Bovet et al. 2002; Van Hoye et al. 2015). Professionals also agreed that feasibility of change is important, and that there are some circumstances where there is "no realistic chance of going outside.' Having a close existing relationship with parents was considered key to successful recruitment of parents

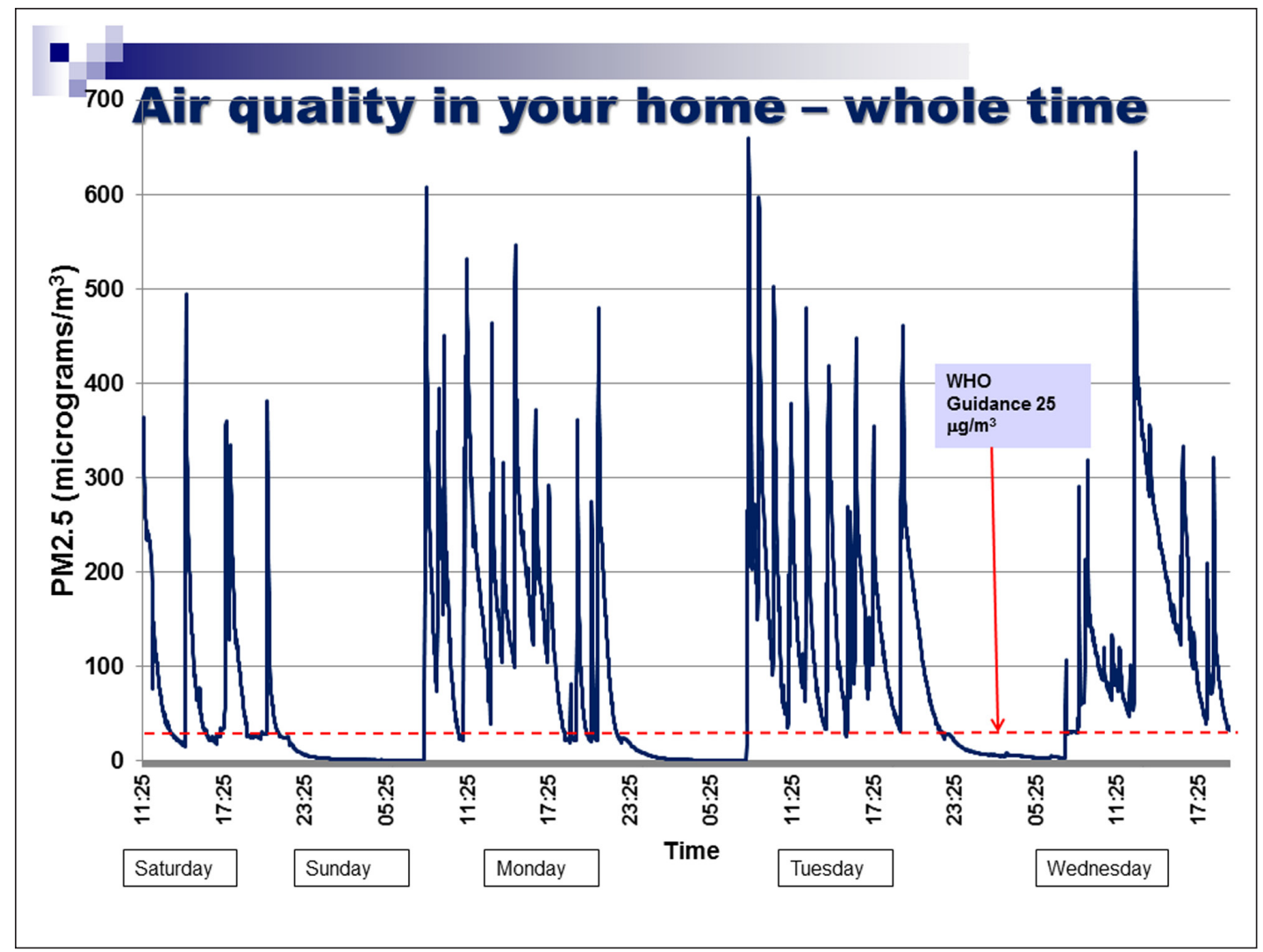

Figure 4: Examples of current feedback package at the time of the needs analysis. 
to air quality feedback studies. Professionals valued the importance of parents being able to see changes in their air quality levels at follow up visits, and spoke of an 'ideal' intervention taking between one to five days. ii. Air quality feedback

Professionals were asked specifically about ways in which current air quality feedback packages (see Figures 4-6) could be improved.

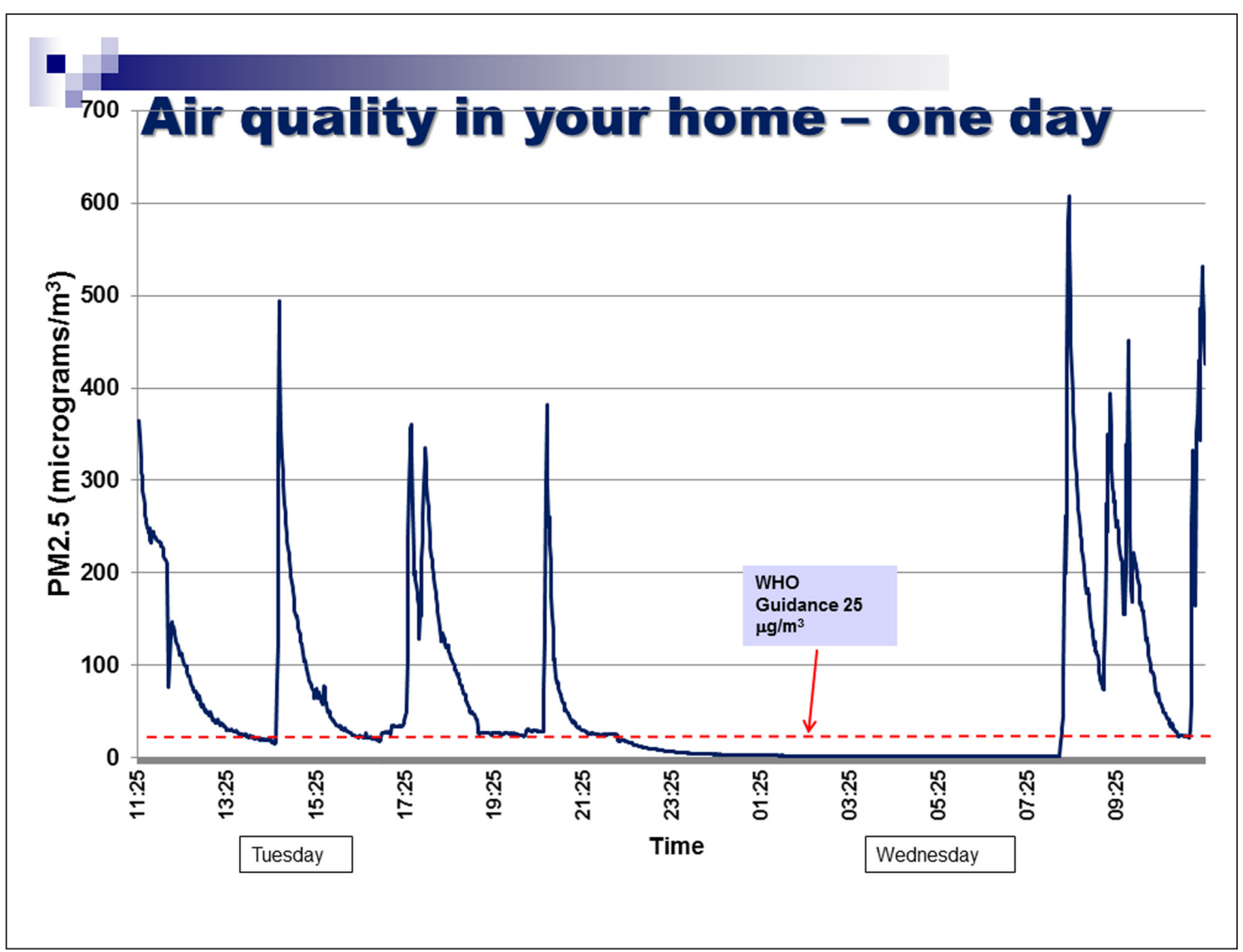

Figure 5: Examples of current feedback package at the time of the needs analysis.

\section{Particulate matter levels in your home}

Total measurement time in your home $=3$ days, 2 hours, 49 mins

$\square$ Average value $=92 \mu \mathrm{g} / \mathrm{m}^{3}$

(more than two times the World Health Organisation guidance limit of $25 \mu \mathrm{g} / \mathrm{m}^{3}$ )

$\square$ Maximum level recorded $=660 \mu \mathrm{g} / \mathrm{m}^{3}$

Total time that your air quality is above the $\mathrm{WHO}$ guidance value $=61 \%$

$\square$ Total time in your house when particle levels were above the average found in Scottish bars before they became smoke-free $=10 \%$

Fine particle levels in your home are above the WHO guidance limit for about 14 hours each day and suggest frequent smoking in your home leads to poor air quality

Figure 6: Examples of current feedback package at the time of the needs analysis. 
Professionals valued being able to discuss peaks in second-hand smoke levels with parents, and the day and time axis enables parents to identify particular events or reasons why second-hand smoke levels changed. Explanations of second-hand smoke levels by day, and across the duration of the time for which the monitor was installed was considered useful. Professionals felt that parents focus more on the visuals of the graph than on the accompanying information.

Most parents found the feedback graph easy to understand. They reiterated the importance of receiving personalised air quality feedback, stating that non-personalised information might not be a sufficient motivator for actual behaviour change. As one parent noted, "If you see a graph of someone else's levels, you could always just say 'well, mine would be lower than that anyway'." Parents suggested using feedback on baseline second-hand smoke levels more explicitly as a motivator for behaviour change and stressed the importance of using non-judgemental language when readings are higher than anticipated. On this basis the air quality feedback package was further developed as per Figures 7-8.

To represent air quality over time in the home, a hybrid visualisation was developed, based on a simplified version of the US Environmental Protection Agency's Air Quality Index (2014) representing hourly average levels of $\mathrm{PM}_{2.5}$, along with a simplified version of Figures 4-6. To allow participants to make a clear connection between recent events in their home and the quality of their air, this visualisation was presented only for the last twenty-four hours of measurement. To emphasise the importance of the average level of $\mathrm{PM}_{2.5}$, a colourful visualisation was developed using the VizHealth toolkit (The Regents of the University of Michigan \& the Robert Wood Johnson Foundation 2014), comparing the average $\mathrm{PM}_{2.5}$ level to the same air quality index used to display hourly average levels.

AFRESH software (The University of Aberdeen, 2016) was developed in tandem with the development of programme materials to enable health/care professionals to download and interpret air quality data, and present air quality feedback to parents. We also developed the AFRESH programme manual (2016) (see Supplementary file 7 - programme manual and materials) providing practical information on how to work with parents through the programme, and how to use the materials as part of the intervention.

\section{iii. The AFRESH programme}

The AFRESH programme consists of 6 modules designed to be delivered using face to face discussion techniques, alongside baseline and follow up measures of household second-hand smoke levels. Parents can self-install air quality monitors (Dylos DC1700) and return them to their health/care contact, eliminating the need for home visits. Figure 9 outlines the AFRESH intervention and accompanying materials. Table 4 shows how the AFRESH intervention and materials related to the performance and change

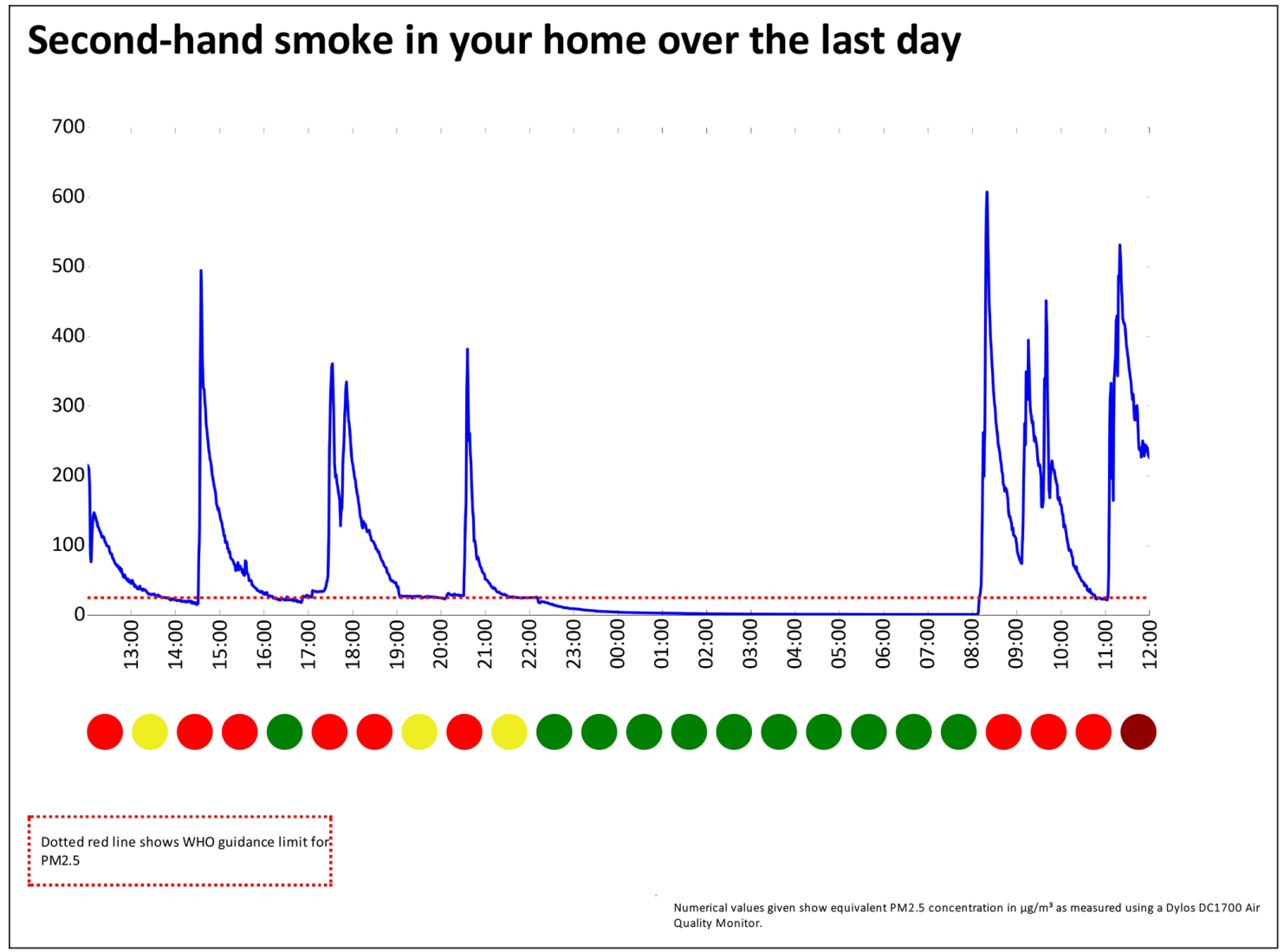

Figure 7: Examples of revised personalised feedback from a home where smoking takes place. Dotted red line shows WHO guidance limit for $\mathrm{PM}_{2.5}$. Numerical values given show equivalent $\mathrm{PM}_{2.5}$ concentrations in $\mu \mathrm{g} / \mathrm{m}^{3}$ as measured using a Dylos DC1700 Air Quality Monitor. 
objectives/methods identified during the intervention mapping process.

The AFRESH programme consists of five contact points over the course of approximately 1 month, although the programme could run over a longer time span if required. Each point of contact ranges from between five and sixty minutes in duration, although the sixty-minute session may be broken down into shorter sessions. Working through four core modules, health/care professionals establish parents' current smoking practices, level of knowledge, and their beliefs and attitudes related to second-hand smoke exposure in the home (Module 1). Parents are then invited to take part in the AFRESH intervention, and they are given an air quality monitor to install in their home for a minimum of 5 days, together with written information on the AFRESH intervention.

The air quality monitor is returned to the health/care professional at the start of Module 2, so that air quality data can be downloaded using the AFRESH software. The health/care professional then arranges a suitable time to provide the parent with personalised air quality feedback. Following discussion of air quality levels in the home, the professional discusses parent facilitators and barriers to creating a smoke-free home. They then work through Module 4 with the parent, explaining that behaviour change is helped by a detailed plan of how parents are going to change their behaviour. The parent then develops a personal smoke-free home action plan, and the care professional encourages them to make a list of 'if-then' plans (i.e. 'If it is a weekday morning, then I will go outside and have a cigarette before my partner goes to work.'). During this module, the parent is encouraged to identify sources of support who will encourage them in their behaviour change attempt.

Between two and four weeks later, parents install the air quality monitor again to record second-hand smoke levels in their home for another minimum of five days. Health/care professionals download the air quality data as before and prepare personalised air quality feedback. When parents receive their feedback this time, they compare it with baseline levels, and review the personal smokefree homes action plan accordingly. The health/care professional praises any success, discusses any benefits and setbacks, and reviews the goal as appropriate. Where a smoke-free home has been obtained, techniques are discussed for maintaining this in the long term.

The AFRESH programme also contains two optional modules. Module 5 contains guidance on creating a smoke-free home with the help of visitors/other household members. It offers advice on effectively raising the issue with others, on skills for dealing with family barriers, and on planning for a smoke-free home together. Module

\section{Your home's average second-hand smoke level}
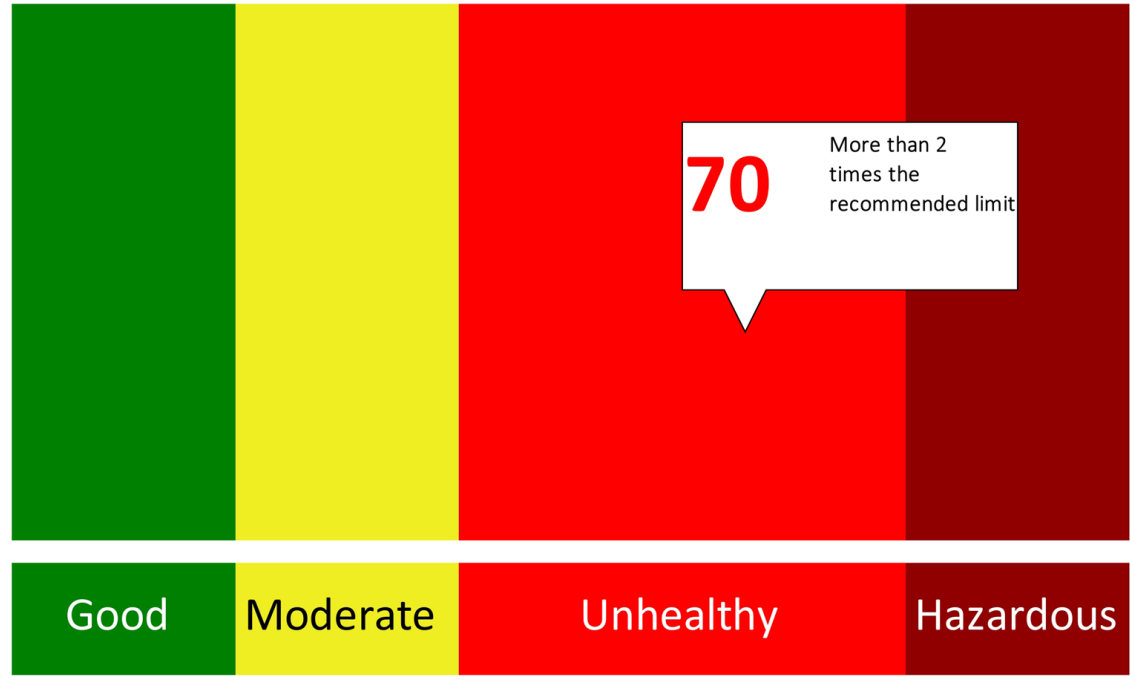

Numerical values given show equivalent PM2.5 concentration in $\mu \mathrm{g} / \mathrm{m}^{3}$ as measured using a Dylos DC1700 Air Quality Monitor. Categories are derived from WHO and US Environmental Protection ABency guidance levels.

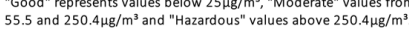

Figure 8: Examples of revised personalised feedback from a home where smoking takes place. Numerical values given show equivalent $\mathrm{PM}_{2.5}$ concentrations in $\mu \mathrm{g} / \mathrm{m}^{3}$ as measured using a Dylos DC1700 Air Quality Monitor. Categories are derived from WHO and US Environmental Protection Agency guidance levels. 'Good' represents values below $25 \mu \mathrm{g} / \mathrm{m}^{3}$, 'Moderate' represents values from 25 to $55.4 \mu \mathrm{g} / \mathrm{m}^{3}$, 'Unhealthy' represents levels between 55.5-250.4 $\mu \mathrm{g} / \mathrm{m}^{3}$ and 'Hazardous' represents values above $250.4 \mu \mathrm{g} / \mathrm{m}^{3}$. 
6 can be used at any time in the programme, should a parent decide that they want to quit smoking. It includes materials based on current cessation guidelines in Scotland (NHS Health Scotland 2017).

One of the outcomes of the semi-structured interviews with professionals conducted during Step 4 was that they needed to be better trained in the skills required to deliver elements of the intervention including dealing with situations where parents are unable to realistically take their smoking outside. On this basis, we developed AFRESH training (available from the authors on request) to accompany the AFRESH programme manual, based on existing materials already utilised by the research team (ASH Scotland, the University of Aberdeen \& the University of Edinburgh 2012) and the British Psychological Society/Department of Health's 'Improving Health: Changing Behaviour' NHS Health Trainer Handbook (Michie et al. 2008). The training included an overview of the theoretical underpinnings for the intervention and a general introduction to the topic area of second-hand smoke exposure in the home.

\section{Discussion}

This article describes the systematic use of the IM protocol (Bartholomew et al. 2016) to develop a theory- and evidence-based smoke-free homes intervention. The AFRESH programme was specifically designed and developed to address the lack of feasible and effective smokefree homes interventions available for use with disadvantaged households. Based on our rapid review findings, the intervention was developed to be delivered by health/care professionals, involving face to face communications with parents. It included MI techniques and a focus on providing parents with personalised air quality feedback. We built on previous studies to develop an arm of the intervention that could be used by parents to support their partners/other household members in assisting with the creation and maintenance of a smoke-free home.

We found that discussion, elaboration, individualisation, goal setting, planning coping responses and building skills for resistance were methods well suited to encouraging smoking parents to create a smoke-free home. We utilised feedback from parents and health/care professionals on the design and execution of air quality monitoring studies, and involved potential AFRESH programme centres from the outset of this work to assist with securing implementation.

In order to take account of identified implementation barriers, we developed a tailored AFRESH training programme, a step-by step guide to delivering the intervention, and a range of tailored support materials to use with parents, depending on their individual needs. We planned an intervention with feedback of personalised air quality levels in the home at baseline, and a short-term follow up measure between two and four weeks later.

During the course of developing the AFRESH programme, the use of IM served as a useful protocol to ensure the integration of theory, evidence and existing practice in this field. It is a thorough process which requires a systematic approach, but when followed step-by step it serves to ensure that all intervention objectives are sufficiently addressed through design and development phases.

\section{Conclusion}

This paper demonstrates that it is feasible to adopt an intervention mapping approach to develop a rigorous, theory- and evidence-based smoke-free homes intervention for use with disadvantaged households.

\section{Additional Files}

The additional files for this article can be found as follows:

- Supplementary file 1: Semi-structured interview questions for use with health/care professionals (Intervention Mapping Step 4). DOI: https://doi. org/10.5334/hpb.20.s 1

- Supplementary file 2: Focus Group Topic Guide - Intervention Mapping Step 4. DOI: https://doi. org/10.5334/hpb.20.s2

- Supplementary file 3: Review on Behavioural Interventions to Reduce Indoor Smoking by Parents. DOI: https://doi.org/10.5334/hpb.20.s3

- Supplementary file 4: Review of Successful Interventions That Have Used Objectively Assessed Feedback to Motivate Health Behaviour Change. DOI: https://doi.org/10.5334/hpb.20.s4

- Supplementary file 5: Review of Qualitative data: SHS exposure (SHSe) in the home. DOI: https://doi. org/10.5334/hpb.20.s5

- Supplementary file 6: IM Step 1: Needs Assessment - Literature Search Strategies. DOI: https://doi. org/10.5334/hpb.20.s6

- Supplementary file 7. Programme manual and materials. DOI: https://doi.org/10.5334/hpb.20.s7

Supplementary file 8. Data replication Package. DOI: https://doi.org/10.5334/hpb.20.s8

\section{Funding Information}

This work was supported by The Medical Research Council (grant number MR/M026159/1).

\section{Competing Interests}

The authors have no competing interests to declare.

\section{References}

ASH Scotland, the University of Aberdeen and the University of Edinburgh. (2012). Creating a smokefree home. REFRESH How to Guide for Professionals working with Families and Children. Retrieved from http://www.ashscotland.org.uk/media/458831/ refresh_howtoguidecreate-a-smokefree-homejan 12.pdf

Bartholomew, L. K., Parcel, G. S., \& Kok, G. (1998). Intervention mapping: A process for developing theory- and evidence based health education programs. Health Education and Behavior, 25(5), 545-563. DOI: https://doi. org/10.1177/109019819802500502

Bartholomew, L. K., Parcel, G. S., Kok, G., Gottlieb, N. H., \& Fernández, M. E. (2011). Planning health 
promotion programs. Mountain View, CA: Mayfield Publishing.

Bartholomew, L. K., Markham, C. M., Ruiter, R. A. C., Fernàndez, M. E., Kok, G., \& Parcel, G. S. (2016). Planning health promotion programs: An Intervention Mapping approach (4th ed.). Hoboken, NJ: Wiley.

Baheiraei, A., Kharaghani, R., Mohsenifar, A., Kazemnejad, A., Alikhana, S., Milani, H. S., \& Hovell, M. F. (2011). Reduction of secondhand smoke exposure among healthy infants in Iran: randomized controlled trial. Nicotine and Tobacco Research, 13(9), 840-847. DOI: https://doi. org/10.1093/ntr/ntp148

Behbod, B., Sharma, M., Baxi, R., Roseby, R., \& Webster, P. (2018). Family and carer smoking control programmes for reducing children's exposure to environmental tobacco smoke. Cochrane Database of Systematic Reviews, 1, CD001746. DOI: https://doi. org/10.1002/14651858.CD001746.pub4

Bovet, P., Perret, F., Cornuz, J., Quilindo, R. N., \& Paccaud, M. D. (2002). Improved smoking cessation in smokers given ultrasound photographs of their own Atherosclerotic plaques. Preventive Medicine, 34(2), 215-220. DOI: https://doi.org/10.1006/ pmed.2001.0976

Brown, N., Luckett, T., Davidson, P. M., \& Di Giacomo, M. (2015). Interventions to Reduce Harm from Smoking with Families in Infancy and Early Childhood: A Systematic Review. International Journal of Environmental Research and Public Health, 12(3), 3091-3119. DOI: https://doi.org/10.3390/ ijerph120303091

Carver, C. S., \& Scheier, M. F. (1982). Control theory: A useful conceptual framework for personalitysocial, clinical, and health psychology. Psychological Bulletin, 92(1), 111-135. DOI: https://doi. org/10.1037//0033-2909.92.1.111

Carver, C. S., \& Scheier, M. F. (1998). On the self-regulation of behaviour. New York, NY: Cambridge University Press. DOI: https://doi.org/10.1017/ CB09781139174794

Conner, M., \& Norman, P. (2017). Health behaviour: Current issues and challenges. Psychology \& Health, 32(8), 895-906. DOI: https://doi.org/10.1080/088 70446.2017.1336240

De Blok, B. M. J., de Greef, M. H. G., ten Hacken, N. H. T., Sprenger, S. R., Postema, K., \& Wempe, J. B. (2006). The effects of a lifestyle physical activity counselling program with feedback of a pedometer during pulmonary rehabilitation in patients with COPD: A pilot study. Patient Education \& Counseling, 61(1), 48-55. DOI: https://doi.org/10.1016/j. pec.2005.02.005

De Bruin, M., Sheeran, P., Kok, G., Hiemstra, A., Prins, J. M., Hospers, H. J., \& van Breukelen, G. J. M. (2012). Self-regulatory processes mediate the intention-behavior relation for adherence and exercise behaviors. Health Psychology, 31(6), 695-703. DOI: https://doi.org/10.1037/a0027425
Deci, E. L., \& Ryan, R. M. (1985). Intrinsic motivation and self-determination in human behaviour. New York: Plenum

Deci, E. L., \& Ryan, R. M. (2008). Facilitating optimal motivation and psychological well-being across life's domains. Canadian Psychology/Psychologie Canadienne, 49(1), 14-23. DOI: https://doi. org/10.1037/0708-5591.49.1.14

Deci, E. L., \& Ryan, R. M. (2012). From self-determination theory. In: P. A. M. Van Lange, A. W. Kruglanski, \& E. T. Higgins (Eds.), Handbook of theories of social psychology, 416-37. Thousand Oaks: Sage.

Dobson, R., O'Donnell, R., De Bruin, M., Turner, S., \& Semple, S. (2017). Using air quality monitoring to reduce second-hand smoke exposure in homes: the AFRESH feasibility study. Tobacco Prevention \& Cessation, 3(June), 117. DOI: https://doi.org/10.18332/ tpc/74645

Emmons, K. M., Hammond, S. K., Fava, J. L., Velicer, W. F., Evans, J. L., \& Monroe, A. D. (2001). A randomized trial to reduce passive smoke exposure in low-income households with young children. Pediatrics, 108(1), 18-24. DOI: https://doi.org/10.1542/ peds.108.1.18

Gee, I., Semple, S., Watson, A., \& Crossfield, A. (2013). Nearly $85 \%$ of tobacco smoke is invisible-a confirmation of previous claims. Tobacco Control, 22(6), 429. DOI: https://doi.org/10.1136/ tobaccocontrol-2012-050475

Harutyunyan, A., Movsisyan, N., Petrosyan, V., Petrosyan, D., \& Stillman, F. (2013). Reducing children's exposure to secondhand smoke at home: A randomized trial. Pediatrics, 132(6), 1071-1080. DOI: https://doi.org/10.1542/peds.2012-2351

Kok, G., Gottlieb, N. H., Peters, G. Y. Y., Mullen, P. D., Parcel, G. S., Ruiter, R. A. C., Fernandez, M. E., Markham, C., \& Bartholomew, L. K. (2016). A Taxonomy of Behaviour Change Methods; an Intervention Mapping Approach. Health Psychology Review, 10(3), 297-312. DOI: https://doi.org/10.10 80/17437199.2015.1077155

Marsh, J., McNeill, A., Lewis, S., Coleman, T., Bains, M., Larwood, A., Purdy, J., \& Jones, L. L. (2016). Protecting children from secondhand smoke: a mixed-methods feasibility study of a novel smokefree home intervention. Pilot and Feasibility Studies, 2(1), 53. DOI: https://doi.org/10.1186/ s40814-016-0094-7

Michie, S., \& Abraham, C. (2004). Interventions to change health behaviours: Evidence-based or evidence inspired? Psychology \& Health, 19(1), 29-49. DOI: https://doi.org/10.1080/0887044031000141199

Michie, S., Rumsey, N., Fussell, A., Hardeman, W., Johnston, M., Newman, S., \& Yardley, L. (2008). Improving health: changing behaviour. NHS health trainer handbook. Manual. Department of Health Publications (Best Practice Guidance: Gateway Ref 9721). Retrieved from http://eprints.uwe.ac.uk/12057/

Ng, J. Y. Y., Ntoumanis, N., Thogersen-Ntoumani, C., Deci, E. L., Ryan, R. M., Duda, J. L., \& Williams, G. C. 
(2012). Self-determination theory and applied to health contexts: A meta-analysis. Perspectives on Psychological Science, 7(4), 325-340. DOI: https:// doi.org/10.1177/1745691612447309

NHS Health Scotland. (2017). A guide to smoking cessation in Scotland 2010. Helping smokers to stop. Brief interventions. Updated 2017. Retrieved from http://www.healthscotland.scot/media/1097/ helping-smokers-to-stop-smoking-2017.pdf

Passey, M. E., Longman, J. M., Robinson, J., Wiggers, J., \& Jones, L. L. (2016). Smoke-free homes: what are the barriers, motivators and enablers? A qualitative systematic review and thematic analysis. British Medical Journal Open, 6(3), e010260. DOI: https://doi.org/10.1136/bmjopen-2015-010 260

Patrick, H., \& Williams, G. C. (2012). Self-determination theory: its application to health behavior and complementarity with motivational interviewing. International Journal of Behavioral Nutrition and Physical Activity, 9(18), 1-12. DOI: https://doi. org/10.1186/1479-5868-9-18

Phillips, R., Amos, A., Ritchie, D., Cunningham-Burley, S., \& Martin, C. (2007). Smoking in the home after the smoke-free legislation in Scotland: qualitative study. British Medical Journal, 335(7619), 553. DOI: https://doi.org/10.1136/bmj.39301.497593.55

Ratschen, E., Thorley, R., Jones, L., Opazo Breton, M., Cook, J., McNeill, A., Britton, J., Coleman, T., \& Lewis, S. (2018). A randomised controlled trial of a complex intervention to reduce children's exposure to secondhand smoke in the home. Tobacco Control, 27, 155-162. DOI: https://doi.org/10.1136/ tobaccocontrol-2016-053279

Rosen, L. J., Myers, V., Winickoff, J. P., \& Knott, J. (2015). Effectiveness of interventions to reduce tobacco smoke pollution in homes: A systematic review and meta-analysis. International Journal of Environmental Research and Public Health, 12, 16043-16059. DOI: https://doi.org/10.3390/ ijerph 121215038

Rowa-Dewar, N., Lumsdaine, C., \& Amos, A. (2015). Protecting children from smoke exposure in disadvantaged homes. Nicotine and Tobacco Research, 17, 496-501. DOI: https://doi.org/10.1093/ntr/ ntu217

Schaalma, H., \& Kok, G. (2009). Decoding health education interventions: the times are a-changin'. Psychology \& Health, 24(1), 5-9. DOI: https://doi. org/10.1080/08870440801995802

Scottish Government. (2016). The Scottish Health Survey 2015: Volume 1: Main Report. Retrieved from: http://www.gov.scot/Publications/2016/09/2764

Semple, S., \& Latif, N. (2014). How Long Does Secondhand Smoke Remain in Household Air: Analysis of $\mathrm{PM}_{2.5}$ Data From Smokers' Homes. Nicotine \& Tobacco Research, 16(10), 1365-1370. DOI: https:// doi.org/10.1093/ntr/ntu089

Semple, S., Turner, S., O'Donnell, R., Adams, L., Henderson, T., Mitchell, S., Lyttle, S., \&
Amos, A. (2018). Using air-quality feedback to encourage disadvantaged parents to create a smoke-free home: Results from a randomised controlled trial. Environment International, 120, 104110. DOI: https://doi.org/10.1016/j.envint.2018. 07.039

The Regents of the University of Michigan and the Robert Wood Johnson Foundation. (2014). Visualising Health. Retrieved from: http://www.vizhealth.org/

The University of Aberdeen. (2016). DylosGUI v0.3.1 software. Retrieved from https://bitbucket.org/ ruaraidhd/dylosgui/src/master/

United States Environmental Protection Agency. (2014). Air Quality Index: A Guide to Air Quality and Your Health. Retrieved August 02, 2018, from: https:// www3.epa.gov/airnow/aqi_brochure_02_14.pdf

Van Hoye, K., Boen, F., \& Lefevre, J. (2015). The impact of different degrees of feedback on physical activity levels: A 4-week intervention study. International Journal of Environmental Research and Public Health, 12(6), 6561-6581. DOI: https://doi.org/10.3390/ ijerph 120606561

Vansteenkiste, M., Williams, G. C., \& Resnicow, K. (2012). Toward systematic integration between self-determination theory and motivational interviewing as examples of top-down and bottom-up intervention development: Autonomy or volition as a fundamental theoretical principle. International Journal of Behavioral Nutrition and Physical Activity, 9(23). DOI: https://doi.org/10.1186/1479-58 68-9-23

WHO Framework Convention Alliance for Tobacco Control. (2005). Secondhand smoke factsheet no 3. Geneva: Framework Convention Alliance for Tobacco Control.

Wilson, I., Ritchie, D., Amos, A., Shaw, A., O'Donnell, R., Mills, L. M., Semple, S. E., \& Turner, S. W. (2013a). 'I'm not doing this for me': mothers' accounts of creating smoke-free homes. Health Education Research, 28(1), 165-78. DOI: https://doi.org/10.1093/her/ cys082

Wilson, I., Semple, S., Mills, L. M., Ritchie, D., Shaw, A., O'Donnell, R., Bonella, P., Turner, S. W., \& Amos, A. (2013b). REFRESH-reducing families' exposure to secondhand smoke in the home: a feasibility study. Tobacco Control, 22(5), e8. DOI: https://doi. org/10.1136/tobaccocontrol-2011-050212

\section{Peer Review Comments}

Health Psychology Bulletin has blind peer review, which is unblinded upon article acceptance. The editorial history of this article can be downloaded here:

- PR File 1. Peer Review History. DOI: https://doi. org/10.5334/hpb.20.pr1

- PR File 2. Peer Review History. DOI: https://doi. org/10.5334/hpb.20.pr2

- PR File 3. Peer Review History. DOI: https://doi. org/10.5334/hpb.20.pr3 
How to cite this article: O'Donnell, R., Dobson, R., de Bruin, M., Turner, S., Booth, L., \& Semple, S. (2019). Development of a SmokeFree Homes Intervention for Parents: An Intervention Mapping Approach. Health Psychology Bulletin, 3(1), pp. 67-86. DOI: https:// doi.org/10.5334/hpb.20

Submitted: 15 September 2018 Accepted: 27 August 2019 Published: 19 December 2019

Copyright: ( 2019 The Author(s). This is an open-access article distributed under the terms of the Creative Commons Attribution 4.0 International License (CC-BY 4.0), which permits unrestricted use, distribution, and reproduction in any medium, provided the original author and source are credited. See http://creativecommons.org/licenses/by/4.0/.

]u[ Health Psychology Bulletin is a peer-reviewed open access journal published by Ubiquity 